\title{
A Validated Method for Identifying Unplanned Pediatric Readmission
}

Katherine A Auger, MD, MSc ${ }^{1}$; Emily L Mueller, MD, MSc ${ }^{2}$; Steven H Weinberg ${ }^{3}$; Catherine Forster, $\mathrm{MD}^{1}$; Anita Shah, $\mathrm{MD}^{1}$; Christine Wolski, $\mathrm{MD}^{1}$; Grant Mussman, $\mathrm{MD}^{1}$; Anna Jolanta Ipsaro, MD, MBE ${ }^{1}$; Matthew M Davis MD, MAPP ${ }^{4}$

\section{Affiliations:}

1 Division of Hospital Medicine, Department of Pediatrics, Cincinnati Children's Hospital Medical Center

2 Center for Pediatric and Adolescent Comparative Effectiveness Research and Division of

Hematology/Oncology, Department of Pediatrics, Indiana University

3 Student, University of Michigan School of Medicine

4 Department of Pediatrics, Department of Internal Medicine, University of Michigan Health System; Gerald R.

Ford School of Public Policy; Institute of Healthcare Policy and Innovation; University of Michigan

Address correspondence to: Katherine Auger, MD

Cincinnati Children's Hospital Medical Center

3333 Burnet Ave, MLC 9016

Cincinnati, OH 45229

Phone 513.636.3753

Fax 513.803.9244

katherine.auger@cchmc.org

Short title: A Validated Method for Identifying Unplanned Readmission

Financial Disclosure: Funding for chart review at one institution as provided by a grant from the Blue Cross Blue Shield Foundation of Michigan. All other data was obtained without specific funding mechanism. The authors have no other financial disclosures.

Conflict of Interest: None

Clinical Trial Registration: $\mathrm{n} / \mathrm{a}$

Key Words: Readmission, pediatric hospitalization, unplanned

Abbreviations: ICD-9-CM: International Classification of Diseases, Ninth Revision, Clinical Modification

This is the author's manuscript of the article published in final edited form as:

Auger, K. A., Mueller, E. L., Weinberg, S. H., Forster, C. S., Shah, A., Wolski, C., ... Davis, M. M. (2016). A Validated Method for Identifying Unplanned Pediatric Readmission. The Journal of Pediatrics, 170, 105-112-2.

http://doi.org/10.1016/j.jpeds.2015.11.051 


\begin{abstract}
Objective: We sought to 1) validate the accuracy of pre-encounter hospital designation as a novel way to identify unplanned pediatric readmissions, and 2) describe the most common diagnoses for unplanned readmissions among children.
\end{abstract}

Methods: We examined all hospital discharges from two tertiary care children's hospitals excluding deaths, normal newborn discharges, transfers to other institutions, and discharges to hospice. We performed blinded medical record review on 641 randomly selected readmissions to validate the pre-encounter planned/unplanned hospital designation. We identified the most common discharge diagnoses associated with subsequent 30-day unplanned readmissions.

Results: Among 166,994 discharges (Hospital A: $n=55,383$; Hospital B: $n=111,611$ ), the 30-day unplanned readmission rate was 10.3\% (Hospital A) and 8.7\% (Hospital B). The hospital designation of "unplanned" was correct in 98\% (Hospital A) and 96\% (Hospital B) of readmissions; the designation of "planned" was correct in 86\% (Hospital A) and 85\% (Hospital B) of readmissions. The most common discharge diagnoses for which unplanned 30-day readmissions occurred were oncologic conditions (up to 38\%) and non-hypertensive congestive heart failure (about 25\%), across both institutions.

Conclusions: Unplanned readmission rates for pediatrics, using a validated, accurate, pre-encounter designation of "unplanned," are higher than previously estimated. For some pediatric conditions unplanned readmission rates are as high as readmission rates reported for adult conditions. Anticipating unplanned readmissions for high-frequency diagnostic groups may help focus efforts to reduce the burden of readmission for families and facilities. 


\section{Background}

Hospital readmissions subject patients and families to the stress and morbidity associated with hospitalization.(1-5) Furthermore, like all hospitalizations, readmissions place patients at risk of hospitalacquired conditions and other nosocomial harm.(6-9) In the era of the Patient Protection and Affordable Care Act, the Centers for Medicare and Medicaid Services have targeted 30-day readmission for cost containment by reducing payments to those hospitals with excess adult readmissions for specific diseases.(10) Some states have also linked Medicaid reimbursement to excess readmission in the pediatric population.(11-13)

Risk-standardized 30 -day readmission rates range from $18 \%$ to $25 \%$ for adults with myocardial infarction, heart failure, and pneumonia.(14) Pediatric readmission rates are lower than those reported for adults: the average all-cause 30-day readmission rate at children's hospitals is $13 \%$.(15) However, some readmissions are planned while others are unplanned (also referred to as "unexpected" readmissions). Unplanned includes both readmissions which are potentially preventable(16) and readmissions which are not planned yet may not be prevented. Prior work estimates unplanned pediatric readmissions to be the majority of readmission cases with only $20-27 \%$ of readmissions being planned.(17, 18) Provider and payer policies designed to improve quality of care and contain costs often focus conceptually on unplanned readmissions. Therefore, it is essential to distinguish unplanned versus planned hospitalizations.(19)

Two recent studies have estimated the rate of unplanned 30-day readmissions for children at $6.5 \%$ and $6.2 \% .(15,20)$ Neither of these studies used validated algorithms to define preventable or unplanned readmissions; rather, the algorithms rely on expert opinion. The first used procedure codes to identify planned readmissions as ones where a procedure was performed that was considered a planned procedure by expert opinion. The second used the Potentially Preventable Readmissions software developed by $3 \mathrm{M}$. This algorithm identifies preventable readmissions using a diagnosis algorithm developed by expert opinion. It is uncertain how well these methods correspond to actual unplanned or preventable readmission status.

Hospitals routinely prepare for planned admissions; they are identified and registered in hospitals' administrative records prior to admission. We defined an unplanned admission as an admission entered into the 
hospital registration system less than 24 hours prior to the patient admission. We sought to 1) validate this definition of unplanned admission as a method of identifying unplanned readmission and 2) characterize rates of unplanned pediatric readmission utilizing this novel validated method. Further, we sought to validate this method of identifying unplanned readmissions at two pediatric institutions to bolster generalizability. Use of a routinely available, accurate, and automated method to identify unplanned readmissions would greatly facilitate reliable measurement of unplanned readmissions and guide interventions to reduce the frequency of such hospitalizations.

\section{Methods}

We examined readmissions from two tertiary care children's hospitals using administrative data. All discharges from January 1, 2006, through December 31, 2012, from Hospital A and all discharges from January 1, 2010, through December 31, 2013, at Hospital B were initially eligible. We chose slightly different time periods for analysis at the two institutions to allow the most recent available data to the investigators in high enough numbers to permit robust analyses of readmissions. Dates of the index admissions were limited to the study period, although readmissions could extend 30 days beyond the study period.

In order to focus on readmissions after discharge to home, we excluded hospitalizations in which the patient died, was transferred to another institution, was discharged against medical advice, or was discharged to hospice. Newborns admitted to a normal newborn service were also excluded, as they do not represent a typical hospitalization for illness. Among newborns admitted to a higher intensity clinical service (e.g., special care nursery or neonatal intensive care), we also excluded newborns with a length of stay <5 days, given the typical length of stay of up to 4 days for uncomplicated delivery via Cesarean-section(21) that would indicate infants for whom precautionary measures had been taken but there was low estimated health risk. We also excluded hospitalizations for patients $>21$ years.

We defined readmission events as any admission within 30 days of discharge after an index hospitalization. All hospitalizations were considered index admissions, such that a single patient may have contributed multiple index admissions over the study period. A planned admission was defined as an admission 
that had been entered into the hospital registration system $>24$ hours prior to the actual admission; we refer to these admissions as planned by "hospital designation." Unplanned admissions were defined as an admission entered into the hospital system $\leq 24$ hours prior to actual admission. A threshold for 24 hours was selected because one hospital in our study utilized this definition of unplanned admission; we sought to validate the method. Admission time is recorded when the patient arrives to the admitting unit by the unit clerk or nurse.

\section{Unplanned Readmission Validation}

In order to validate the hospital designation of unplanned versus planned readmission, we utilized the gold standard of in-depth medical record review on a subset of $2.5 \%$ of readmissions at each institution. At Hospital A we reviewed 211 readmissions, block randomized by readmission designation (140 unplanned and 71 planned by hospital designation). At Hospital B we reviewed 430 readmissions, block randomized by readmission designation (287 unplanned and 143 planned).

In assessing unplanned readmission status, we did not assess preventability or relatedness. Specific clinical scenarios were defined as planned versus unplanned a priori: any admission where the admission was planned at least 24 hours prior to the actual admission was considered planned. For example, admissions for planned procedures (regardless of when the procedure would occur) were considered planned. As such, an organ transplant, which is planned but the timing is unknown, was classified in chart review as planned. Conversely, if a patient presented to the hospital for a planned infusion or procedure (e.g., chemotherapy) but was discovered to have an acute illness (e.g., febrile with neutropenia), the hospitalization would be classified as unplanned. Medical record review included clinic notes prior to admission, telephone notes, emergency room documentation, as well as the admission history and physical. Chart reviewers were blinded to the timing of hospital registration for each admission and thus also to the hospital's designation of planned or unplanned.

For medical record review, at both institutions one reviewer (KA) was responsible for the training of all other reviewers. At both institutions, all reviewers reviewed example training medical records to ensure consistency. Any discrepancies on the training charts were discussed with the first author for further clarification. The reviewers recorded dichotomous answers for each readmission "planned" or "unplanned." One reviewer examined each medical record (at Hospital A KA or SW; at Hospital B KA, CF, AS, CW, GM, or 
AJI). Two randomly assigned reviewers independently reviewed one-half of the medical records at Hospital B to calculate a Kappa statistic. For the minority of readmissions where two reviewers did not agree, all reviewers reviewed the medical records independently and came to consensus.

\section{Describing Readmission Rates}

We calculated the 7- and 30-day unplanned readmission rates at each hospital from the entire administrative dataset (not just those charts selected for medical record review). Primary discharge diagnoses for the index hospitalizations (i.e., the first discharge diagnosis listed) were grouped using the clinical classification software (CCS) developed by HCUP.(22) We calculated 30-day total and unplanned readmission rates by CCS grouping. We also calculated the proportion of readmissions that were unplanned, by CCS code (i.e., of the index admissions that resulted in any readmission, the percentage of the readmissions that were unplanned.). For example at Hospital A, a hospitalization for diabetes mellitus was followed by a 30-day readmission in $4.7 \%$ of instances. Of all of the readmissions for diabetes mellitus, $100 \%$ of the readmissions were unplanned; therefore, the unplanned readmission rate was $4.7 \%$. To describe attributes of patients who were readmitted within 30 days, we performed chi square analysis at the patient level, using bootstrapping to randomly select one admission per patient (see Appendix for additional methods; online only).

Finally, we performed a sensitivity analysis limiting the study period to the overlapping time period at both hospitals (Jan 2010 to Dec 2012). Institutional Review Board approval was obtained at both institutions.

\section{Results}

The initial study sample included 57,715 discharges from Hospital A and 114,883 from Hospital B. After applying exclusion criteria (Figure 1; online only), a total of 55,383 discharges for 32,112 unique patients from Hospital A and 111,611 discharges for 65,989 unique patients from Hospital B remained.

\section{Unplanned Readmission Validation}

The hospital designation of "unplanned" was correct (hospital designation sensitivity) in 129 of 132 (98\%) and 263 of $275(96 \%)$ of the readmissions by chart review at Hospital A and Hospital B, respectively. 
The hospital designation of "planned" was correct (hospital designation specificity) in 68 out of 79 (86\%) and 131 of $155(85 \%)$ of readmissions by chart review at Hospital A and Hospital B, respectively (Table 1). The kappa statistic for inter-rater reliability was excellent, at 0.89 .

\section{Readmission Rates}

The all-cause 30-day readmission rate was $14.9 \%$ at Hospital A and 14.5\% at Hospital B. The 30-day unplanned readmission rate based on the hospital designation was $10.3 \%$ at Hospital A and $8.7 \%$ at Hospital B. Thus, the percentage of 30-day readmissions which were unplanned was $69 \%$ at Hospital A and $60 \%$ at Hospital B. The 7-day unplanned readmission rates were $4.3 \%$ and $3.5 \%$ at Hospital A and B, respectively. Additionally, in a sensitivity analysis limited to the overlapping time period at both hospitals, the unplanned 30day readmission rates of $10.2 \%$ (Hospital A) and an $8.7 \%$ (Hospital B).

Demographics of children at the time of their hospitalizations are presented in Table 2. Both hospitals care for a predominance of non-Hispanic white patients. Hospital A had a majority of privately insured hospitalizations; approximately half of hospitalizations at Hospital B were in patients with Medicaid. Age category and payer type were associated with readmission in bivariate analyses at both hospitals (Table 2).

Examining unplanned readmission rates, 20 diagnostic groups had unplanned readmission rates of $>20 \%$ in at least one of the two institutions (Figure 2). Neoplastic conditions had unplanned readmission rates as high as $38 \%$ and constituted half of the 10 conditions with most common subsequent unplanned readmissions. Approximately one-quarter of hospitalizations for congestive heart failure were followed by unplanned readmissions at both institutions. The majority of heart failure admissions occurred in young children (age $<3$ years) at both hospitals. Some discharge diagnoses had all-cause (planned + unplanned) readmission rates as high as $80 \%$. Neoplastic conditions had the highest all-cause readmission rates (Figure 3; online only).

\section{Unplanned readmissions as a share of all readmissions}

Several acute conditions and acute presentations of chronic diseases had very high proportions (>90\%) of readmissions identified as unplanned at both institutions, including diabetes, appendicitis, and acute 
bronchiolitis (Table 3). Additionally, several psychiatric illnesses had a high proportion of readmissions that were unplanned at Hospital B, which has an inpatient child psychiatric facility.

\section{Discussion}

In this analysis of more than 166,000 discharges from two children's hospitals, unplanned readmission rates were substantively higher than previously reported rates of unplanned readmission and potentially preventable readmission.(15, 20) Systematically excluding readmissions based on post hoc diagnosis likely disregards a substantive number of unplanned pediatric readmissions. This difference is presumably due to differences in measurement definition; previous studies have used algorithms based on post-hoc determination from expert consensus. We used an administrative indicator that is widely available at hospitals and was present in $100 \%$ of all hospitalizations sampled for this analysis. The accuracy of the administrative indicator was high, with correct designations in $>95 \%$ of unplanned readmissions and $85 \%$ of planned readmissions at two separate institutions. Our administrative indicator was better able to distinguish planned and unplanned readmissions than a recently published algorithm to identify planned readmissions for adults.(23) The broad availability of an indicator with such accuracy amplifies its potential value as a measure of readmission across institutions. Moreover, unplanned readmissions constituted the majority (60-69\%) of all 30-day pediatric readmissions.

Unplanned readmission rates after hospitalization for several neoplastic conditions and congestive heart failure were as high or higher than readmission rates reported for primary adult conditions (pneumonia, acute myocardial infarction, and congestive heart failure).(14) Additionally, among index hospitalizations with a subsequent readmission, conditions with acute (e.g., appendicitis) or acute-on-chronic presentations (e.g., diabetes) had the highest percentage of unplanned readmissions.

In our study, neoplastic conditions were among the diagnoses with the highest 30-day unplanned readmission rates. Patients with cancer experience a wide range of treatment and disease-related complications that may lead to readmission. A common reason for readmission in pediatric cancer patients is febrile neutropenia, $(24,25)$ a potentially life-threatening complication of chemotherapy. $(26,27)$ While it is not likely that all unplanned cancer readmissions are preventable, future research may illuminate differences in unplanned 
readmission patterns after hospitalizations for patients with neoplasms to determine reasons for heterogeneous outcomes at the institutional level. This research could inform quality metrics specific to children with cancer and other populations of pediatric patients with high unplanned readmission rates.

\section{Unplanned Readmission and Quality Improvement}

Our method of distinguishing planned from unplanned readmission has several potential benefits. First, it is broadly feasible; hospitals only need the ability to determine when a patient is registered in the hospital system and when the patient is actually admitted to determine planned/unplanned status. Therefore, hospitals can routinely populate the indicator that we used for their analyses of unplanned readmission events. Second, the method we identified can be implemented in real time. Previously published methods to identify unplanned readmissions rely on post-hoc data to determine planned/unplanned status based on either discharge diagnoses or procedures during admission. $(20,28)$ Our method has the added benefit that the unplanned/planned designation is known at admission. The ability to define real-time outcomes is essential for quality improvement methodologies that could be applied during hospitalizations in ways to reduce subsequent risk of readmission for individual patients. For example, QI interventions to reduce readmission may involve care provider notification of readmission. Real time notification of unplanned readmission allows for information to be gathered from the patient and family during the readmission. Restricting these notifications to only the unplanned readmissions may enhance the usefulness to both clinicians and QI specialists.

An alternative approach for quality improvement projects aimed to decrease pediatric readmission would be to focus on conditions where the majority of readmissions are unplanned. In our study, we found acute illnesses and acute exacerbations of chronic conditions have the highest proportions of readmissions that were unplanned (Table 3). Such conditions include diagnoses with high readmission rates (e.g., sickle cell disease) and those with low readmission rates (e.g., diabetes and appendicitis). The key insight offered by our findings is that identifying clinical domains where unplanned readmissions constitute a higher proportion of total readmissions may indicate diseases or types of hospitalizations to which changes in process of care might result in decreased readmissions. 
Unplanned readmissions include readmissions that are potentially preventable as well as unexpected readmissions that would not be preventable. Administrative algorithms to identify preventability are complex. Even identifying readmission relatedness is difficult with administrative data. For example, a patient admitted with bronchiolitis may be readmitted with bronchiolitis or with dehydration. Both diagnoses may represent a potentially preventable, related readmission; however, understanding the relationship without medical record review is challenging. Future work focusing on refining and validating algorithms to identify preventable readmissions in administrative data is critically important to advancing applied methods in this realm of practice and policy.

\section{Unplanned Readmissions and Health Policy}

Distinguishing unplanned from planned readmissions is essential for implementation of new health policy initiatives designed to hold hospitals accountable for patients' post-discharge courses. If readmission penalties include planned readmissions, hospitals may delay planned readmissions in order to avoid the financial consequences. While it is unlikely hospitals would delay urgent care, it is possible to delay elective planned admissions beyond a 30-day period to avoid penalty. However, such decisions may have unintended negative consequences for children's health.

Additionally, it is highly plausible that an institution's case mix would directly affect the percentage of unplanned readmissions. In our data, children with certain diagnoses (including several oncologic diagnoses) have high rates of unplanned readmission. Our findings bolster the argument for appropriate severity adjustments in readmission penalty policy.

Our study must be considered in the context of several limitations. First, as with any study relying on administrative records, accurate diagnostic coding is essential for reliable conclusions. Some differences in coding practices are noted between the two institutions. For example, at Hospital A a common primary discharge diagnosis code was a chemotherapy V code while at Hospital B chemotherapy was never used as a primary discharge code. Nevertheless, neoplastic conditions (either chemotherapy or specific malignancies) were common for all readmissions and for unplanned readmissions at both institutions. Second, our algorithm had rare misclassification of unplanned readmissions, such that a few readmissions which were categorized as 
unplanned readmissions were actually reclassified as planned readmissions in chart review. Therefore, the true unplanned readmission rate may be slightly lower than the unplanned readmission rate calculated by the hospital designation algorithm. Nevertheless, even if accounting for this minor misclassification, unplanned readmission comprises the majority of pediatric readmissions at both institutions. This finding is consistent with other pediatric readmission studies. Third, this study was performed at two children's hospitals and there may be variations that exist across other institutions, thereby limiting generalizability. However, this study represents one of the first multi-center studies of pediatric readmission involving medical record review. Additionally, there are some important differences between the two hospitals including the inclusion of an inpatient psychiatric facility at Hospital B and the existence of a large tertiary care labor and delivery unit at Hospital A (even though normal births were excluded from our analysis). Given the findings related to psychiatric readmission, further study of these conditions is warranted.

We also relied on retrospective medical record review as our gold standard. While retrospective chart review is only as good as the information contained in the medical record, the fact that we had excellent reviewer agreement indicates a high level of reliability in our gold standard. Given the large number of diagnoses, we were not able to validate the unplanned readmission flag for each diagnosis. Rather, we demonstrated excellent fidelity in the overall ability to identify unplanned readmission. Additionally, we chose slightly different time periods for analysis. A sensitivity analysis limited to the overlapping time period at both institutions revealed no differences in unplanned readmission rates for the two institutions over their respective broader time periods. Finally, the designation of unplanned readmission is currently available at hospitals but not routinely included in claims data. Therefore, for broad policy implementation, hospitals would have to report this information with claims data or other multiple institution databases.

\section{Conclusion}

Utilizing timing of hospital registration in administrative records is an accurate, widely available, realtime way to distinguish unplanned versus planned pediatric readmissions. This designation may be a viable method for accurately calculating unplanned pediatric readmission rates across most hospitals. Hospitalizations 
for certain pediatric conditions including neoplasms and congestive heart failure have unplanned readmission rates as high as those for adult populations. These conditions, and other conditions for which unplanned readmissions constitute the vast majority of readmissions, may prove to be the most fruitful for interventions designed to improve care. 
References

1. Diaz-Caneja A, Gledhill J, Weaver T, Nadel S, Garralda E. A child's admission to hospital: a qualitative study examining the experiences of parents. Intensive Care Med. 2005;31(9):1248-54.

2. Lapillonne A, Regnault A, Gournay V, Gouyon JB, Gilet H, Anghelescu D, et al. Impact on parents of bronchiolitis hospitalization of full-term, preterm and congenital heart disease infants. BMC pediatrics. 2012;12:171.

3. Leader S, Jacobson P, Marcin J, Vardis R, Sorrentino M, Murray D. A method for identifying the financial burden of hospitalized infants on families. Value Health. 2002;5(1):55-9.

4. Leidy NK, Margolis MK, Marcin JP, Flynn JA, Frankel LR, Johnson S, et al. The impact of severe respiratory syncytial virus on the child, caregiver, and family during hospitalization and recovery. Pediatrics. 2005;115(6):1536-46.

5. Rennick JE, Johnston CC, Dougherty G, Platt R, Ritchie JA. Children's psychological responses after critical illness and exposure to invasive technology. Journal of developmental and behavioral pediatrics : JDBP. 2002;23(3):133-44.

6. Brennan TA, Leape LL, Laird NM, Hebert L, Localio AR, Lawthers AG, et al. Incidence of adverse events and negligence in hospitalized patients. Results of the Harvard Medical Practice Study I. N Engl J Med. 1991;324(6):370-6.

7. Kohn LT, Corrigan J, Donaldson MS. To err is human : building a safer health system. Washington, D.C.: National Academy Press; 2000. xxi, 287 p. p.

8. Landrigan CP, Parry GJ, Bones CB, Hackbarth AD, Goldmann DA, Sharek PJ. Temporal trends in rates of patient harm resulting from medical care. N Engl J Med. 2010;363(22):2124-34.

9. Magill SS, Edwards JR, Bamberg W, Beldavs ZG, Dumyati G, Kainer MA, et al. Multistate pointprevalence survey of health care-associated infections. N Engl J Med. 2014;370(13):1198-208.

10. Centers for Medicare and Medicaid Services. Readmissions Reduction Program 2013 [cited 2013 Nov 2]. Available from: http://www.cms.gov/Medicare/Medicare-Fee-for-Service-

Payment/AcuteInpatientPPS/Readmissions-Reduction-Program.html.

11. Illinois Department of Healthcare and Family Services. Potentially Preventable Readmissions (PPRs) Policy and Calculations 2012 [cited 2013 September 27]. Available from:

http://www2.illinois.gov/hfs/SiteCollectionDocuments/PPRSlides.pdf.

12. New York State Department of Health Division of Quality and Evaluation Office of Health Insurance Programs. Potentially Preventable Hospital Readmissions Among Medicaid Recipients: New York State, 20072007 [cited 2013 September 27]. Available from:

http://www.health.ny.gov/health care/managed care/reports/statistics data/2hospital readmissions.p df.

13. Texas Health and Human Services Commission. Potentially Preventable Readmisions in the Texas Medicaid Population, State Fiscal Year 20112012 [cited 2013 September 27]. Available from: http://www.hhsc.state.tx.us/reports/2012/PPR-Readmissions-FY2011.pdf.

14. Krumholz HM, Lin Z, Keenan PS, Chen J, Ross JS, Drye EE, et al. Relationship between hospital readmission and mortality rates for patients hospitalized with acute myocardial infarction, heart failure, or pneumonia. Jama. 2013;309(6):587-93.

15. Gay JC, Agrawal R, Auger KA, Del Beccaro MA, Eghtesady P, Fieldston ES, et al. Rates and Impact of Potentially Preventable Readmissions at Children's Hospitals. J Pediatr. 2015;166(3):613-9 e5.

16. Hain PD, Gay JC, Berutti TW, Whitney GM, Wang W, Saville BR. Preventability of early readmissions at a children's hospital. Pediatrics. 2013;131(1):e171-81.

17. Gay JC, Hain PD, Grantham JA, Saville BR. Epidemiology of 15-Day Readmissions to a Children's Hospital. Pediatrics. 2011;127(6):e1505-12.

18. Brittan M, Martin SE, Shmerling J. Hospital readmission rates. Health affairs. 2014;33(12):2266.

19. Auger KA, Simon TD, Cooperberg D, Gay J, Kuo DZ, Saysana M, et al. Summary of STARNet:

Seamless Transitions and (Re)admissions Network. Pediatrics. 2015;135(1):164-75. 
20. Berry JG, Toomey SL, Zaslavsky AM, Jha AK, Nakamura MM, Klein DJ, et al. Pediatric readmission prevalence and variability across hospitals. Jama. 2013;309(4):372-80.

21. The American College of Obstetricians and Gynecologists. Frequently asked questions labor, delivery, and postpartum care [cited 2014 4/30]. Available from:

https://http://www.acog.org/ /media/For Patients/faq006.pdf?dmc=1\&ts=20140430T1447281803.

22. HCUP: Healthcare Cost and Utilization Project. Clinical Classifications Software (CCS) for ICD-9-CM [4/14/2014]. Available from: http://www.hcup-us.ahrq.gov/toolssoftware/ccs/ccs.jsp.

23. Horwitz LI, Grady JN, Cohen DB, Lin Z, Volpe M, Ngo CK, et al. Development and Validation of an Algorithm to Identify Planned Readmissions From Claims Data. J Hosp Med. 2015;10(10):670-7.

24. Basu SK, Fernandez ID, Fisher SG, Asselin BL, Lyman GH. Length of stay and mortality associated with febrile neutropenia among children with cancer. Journal of clinical oncology : official journal of the American Society of Clinical Oncology. 2005;23(31):7958-66.

25. Klaassen RJ, Goodman TR, Pham B, Doyle JJ. "Low-risk" prediction rule for pediatric oncology patients presenting with fever and neutropenia. Journal of clinical oncology : official journal of the American Society of Clinical Oncology. 2000;18(5):1012-9.

26. Bodey GP, Buckley M, Sathe YS, Freireich EJ. Quantitative relationships between circulating leukocytes and infection in patients with acute leukemia. Ann Intern Med. 1966;64(2):328-40.

27. Mullen CA. Which children with fever and neutropenia can be safely treated as outpatients? British journal of haematology. 2001;112(4):832-7.

28. Goldfield NI, McCullough EC, Hughes JS, Tang AM, Eastman B, Rawlins LK, et al. Identifying potentially preventable readmissions. Health care financing review. 2008;30(1):75-91. 


\section{Table 1}

Assessment of Accuracy for Hospitals' Administrative Designation of Planned and Unplanned Readmissions, Using Medical Record Review

Hospital A: Hospital designation of unplanned readmission is correct in 129 of $132(98 \%)$ readmissions. Hospital designation of planned is correct in and 68 out of 79 (86\%) readmissions.

\begin{tabular}{|c|c|c|c|c|}
\hline & \multicolumn{2}{|c|}{ By medical record review } & \multirow[b]{2}{*}{ Total } \\
\hline & & Unplanned & Planned & \\
\hline \multirow{4}{*}{$\begin{array}{l}\text { By hospital } \\
\text { designation }\end{array}$} & Unplanned & 129 & 11 & 140 \\
\hline & Planned & 3 & 68 & 71 \\
\hline & Total & 132 & 79 & 211 \\
\hline & & $\begin{array}{l}\text { Sensitivity for } \\
\text { identifying } \\
\text { unplanned } \\
\text { readmission=98\% }\end{array}$ & $\begin{array}{l}\text { Specificity for } \\
\text { identifying } \\
\text { unplanned } \\
\text { readmission }=86 \%\end{array}$ & \\
\hline
\end{tabular}

Hospital B: Hospital designation of unplanned readmission is correct in 263 of 275 (96\%) readmissions. Hospital designation of planned is correct in 131 of $155(85 \%)$ readmissions.

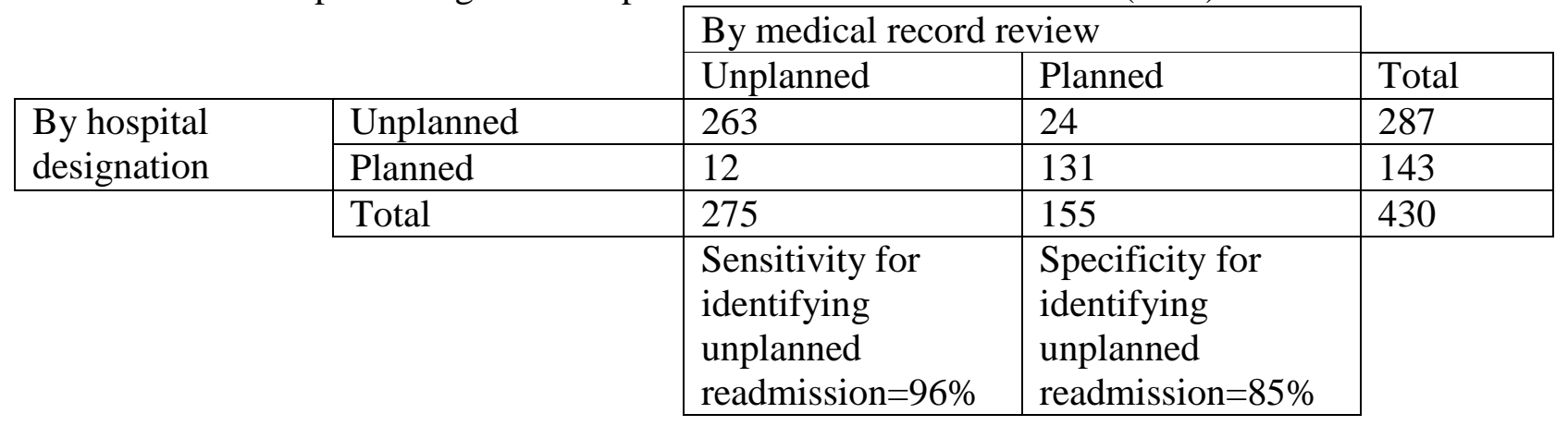


Table 2: Patient demographic characteristics at time of hospitalizations with and without a subsequent unplanned readmission within 30 days

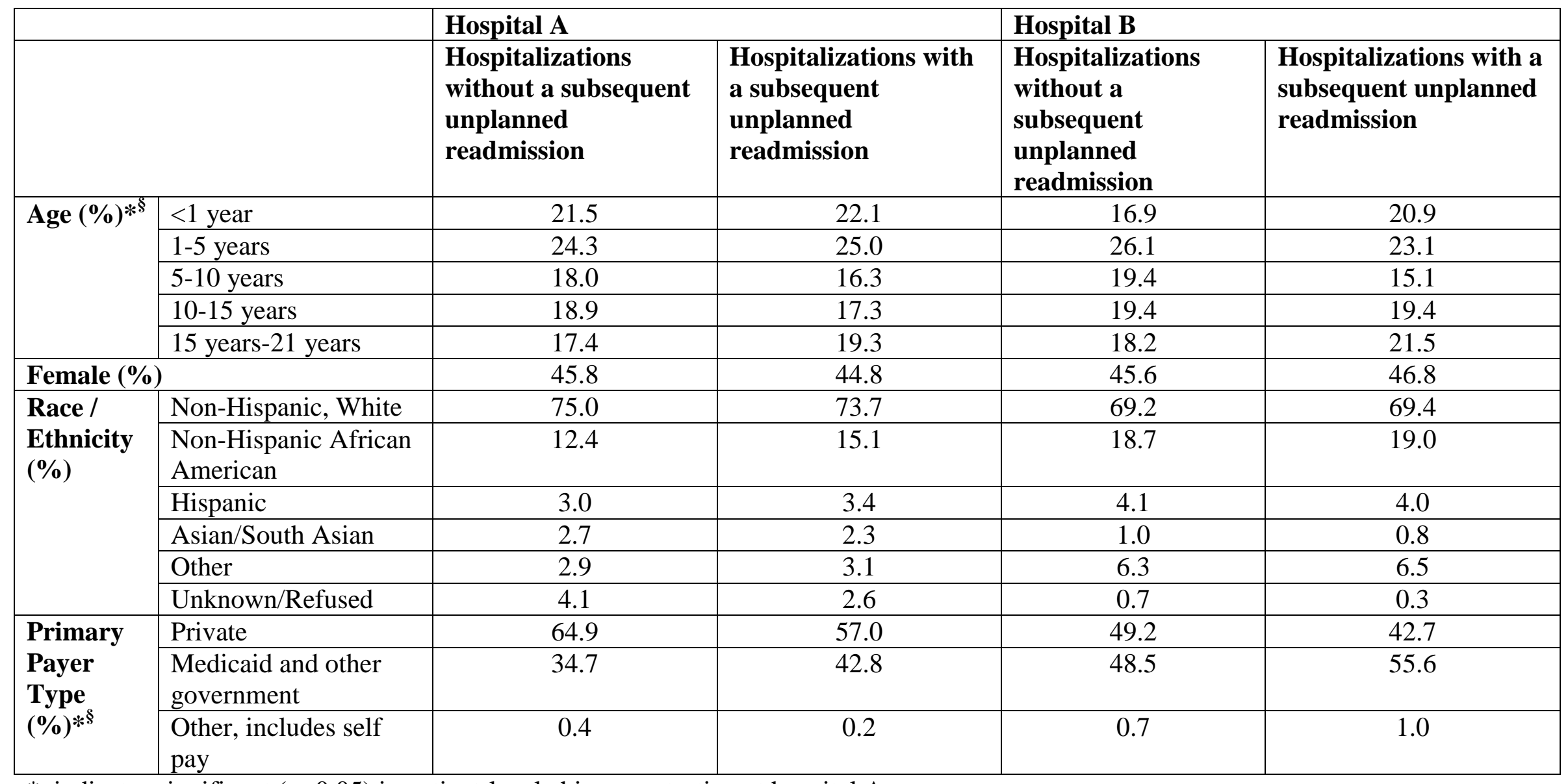

* indicates significant $(\mathrm{p}<0.05)$ in patient-level chi square testing at hospital A

$\S$ indicates significant $(\mathrm{p}<0.05)$ in patient-level chi square testing at hospital B 
Table 3: Among index hospitalizations resulting in a 30-day readmission, proportion of readmissions which were unplanned readmissions by index primary discharge diagnosis*

\begin{tabular}{|c|c|c|c|c|c|c|c|}
\hline \multicolumn{4}{|l|}{ Hospital A } & \multicolumn{4}{|l|}{ Hospital B } \\
\hline $\begin{array}{l}\text { Diagnosis, } \\
\mathrm{n}=\text { number of readmissions }\end{array}$ & $\begin{array}{l}\text { All-cause } \\
\text { (planned } \\
\text { and } \\
\text { unplanned) } \\
\text { readmission } \\
\text { rates }\end{array}$ & $\begin{array}{l}\text { Unplanned } \\
\text { Readmission } \\
\text { rate }(\%)\end{array}$ & $\begin{array}{l}\text { Percentage of } \\
\text { readmissions } \\
\text { that were } \\
\text { unplanned } \\
(\%)\end{array}$ & $\begin{array}{l}\text { Diagnosis, } \\
\mathrm{n}=\text { number of readmissions }\end{array}$ & $\begin{array}{l}\text { All-cause } \\
\text { (planned } \\
\text { and } \\
\text { unplanned) } \\
\text { readmission } \\
\text { rates }\end{array}$ & $\begin{array}{l}\text { Unplanned } \\
\text { Readmission } \\
\text { rate }(\%)\end{array}$ & $\begin{array}{l}\text { Percentage of } \\
\text { readmissions } \\
\text { that were } \\
\text { unplanned } \\
(\%)\end{array}$ \\
\hline $\begin{array}{l}\text { Diabetes mellitus with } \\
\text { complications }(n=32)\end{array}$ & 4.7 & 4.7 & 100 & $\begin{array}{l}\text { Impulse control disorders } \\
(\mathrm{n}=43)\end{array}$ & 13.6 & 13.6 & 100.0 \\
\hline $\begin{array}{l}\text { Appendicitis and other } \\
\text { appendiceal conditions }(\mathrm{n}=57)\end{array}$ & 7.1 & 6.7 & 94.7 & $\begin{array}{l}\text { Meningitis } \\
(\mathrm{n}=29)\end{array}$ & 9.2 & 9.2 & 100.0 \\
\hline Sickle cell anemia $(\mathrm{n}=106)$ & 24.3 & 23.0 & 94.3 & $\begin{array}{l}\text { Schizophrenia and other } \\
\text { psychotic disorders } \\
(\mathrm{n}=66)\end{array}$ & 17.5 & 17.2 & 98.5 \\
\hline Acute bronchiolitis $(n=66)$ & 6.7 & 6.3 & 93.9 & $\begin{array}{l}\text { Acute bronchiolitis } \\
(\mathrm{n}=139)\end{array}$ & 6.8 & 6.6 & 97.1 \\
\hline Asthma $(n=64)$ & 4.4 & 4.1 & 93.8 & $\begin{array}{l}\text { Mood disorders } \\
(\mathrm{n}=521)\end{array}$ & 10.8 & 10.3 & 95.4 \\
\hline $\begin{array}{l}\text { Respiratory failure, } \\
\text { insufficiency, arrest }(n=57)\end{array}$ & 18.8 & 17.4 & 93.0 & $\begin{array}{l}\text { Diabetes mellitus with } \\
\text { complications } \\
(\mathrm{n}=42)\end{array}$ & 4.18 & 4.0 & 95.2 \\
\hline Cystic fibrosis $(n=85)$ & 10.8 & 9.9 & 91.8 & $\begin{array}{l}\text { Appendicitis and other } \\
\text { appendiceal conditions } \\
(\mathrm{n}=62)\end{array}$ & 3.8 & 3.6 & 95.2 \\
\hline $\begin{array}{l}\text { Intestinal obstruction without } \\
\text { hernia }(\mathrm{n}=55)\end{array}$ & 13.1 & 11.9 & 90.9 & $\begin{array}{l}\text { Pneumonia (except that } \\
\text { caused by tuberculosis or } \\
\text { sexually transmitted disease) } \\
(\mathrm{n}=77)\end{array}$ & 6.6 & 6.1 & 92.2 \\
\hline Abdominal pain $(n=32)$ & 9.0 & 8.2 & 90.6 & $\begin{array}{l}\text { Headache; including } \\
\text { migraine } \\
(\mathrm{n}=76)\end{array}$ & 10.1 & 9.1 & 90.8 \\
\hline \multirow[t]{2}{*}{$\begin{array}{l}\text { Genitourinary congenital } \\
\text { anomalies }(n=32)\end{array}$} & 8.1 & 7.4 & 90.6 & $\begin{array}{l}\text { Other perinatal conditions } \\
(\mathrm{n}=50)\end{array}$ & 7.6 & 6.8 & 90.0 \\
\hline & & & & $\begin{array}{l}\text { Skin and subcutaneous } \\
\text { tissue infections }(n=30)\end{array}$ & 3.0 & 2.7 & 90.0 \\
\hline
\end{tabular}

*Top 10 highest percentages of readmissions that were unplanned presented. Diagnoses only included in tables if the there are at least 25 readmissions. Diagnoses are grouped according to the clinical classification software. ${ }^{22}$ 


\section{Hospital A}

57,715

Discharges in patients

$<21$ years excluding

infants on Well Baby

Service

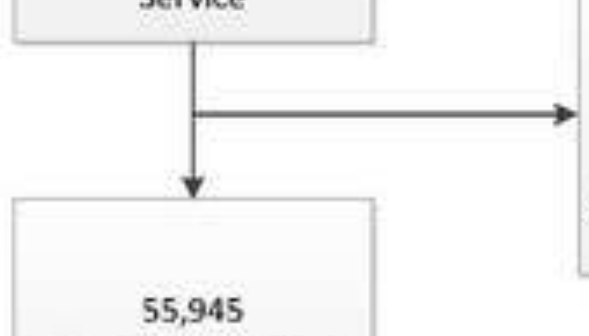

Discharges to home

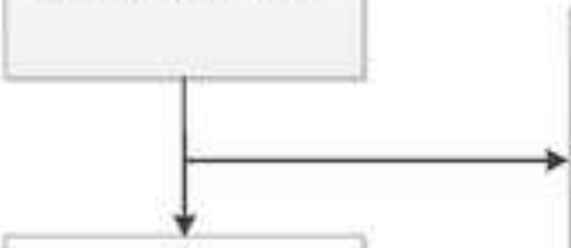

55,383

Discharges included

from 32,112 patients

\section{1,770}

Hospitalizations resulting in death, discharges against medical advice.

transfers, and discharges to hospice

\section{2}

Short stay newborn discharges

211

Readmissions randomly selected for medical record review

\section{Hospital B}

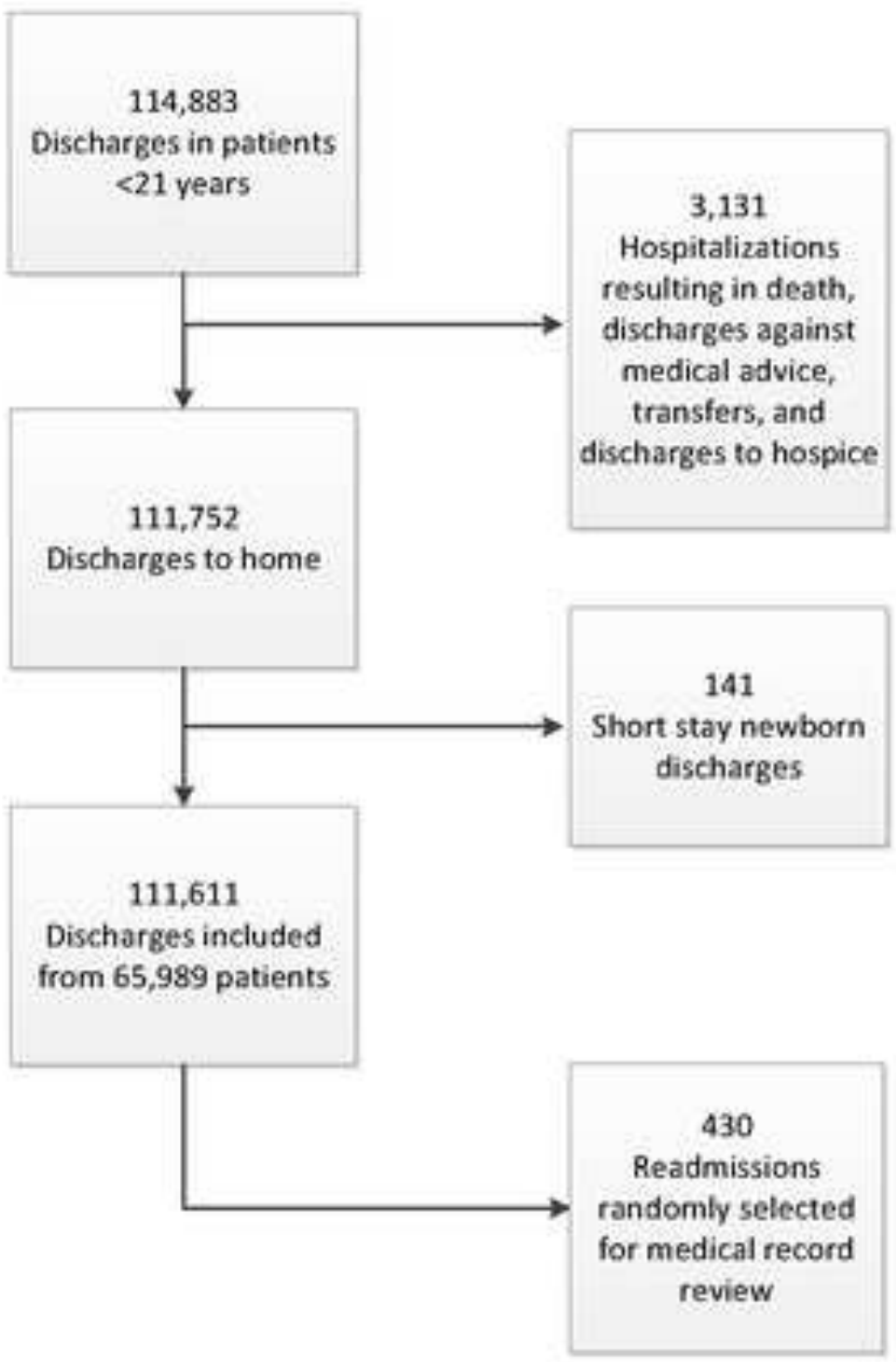




\section{Figure 2. Highest 30-Day Unplanned Readmission Rates by Index Discharge Diagnosis*}

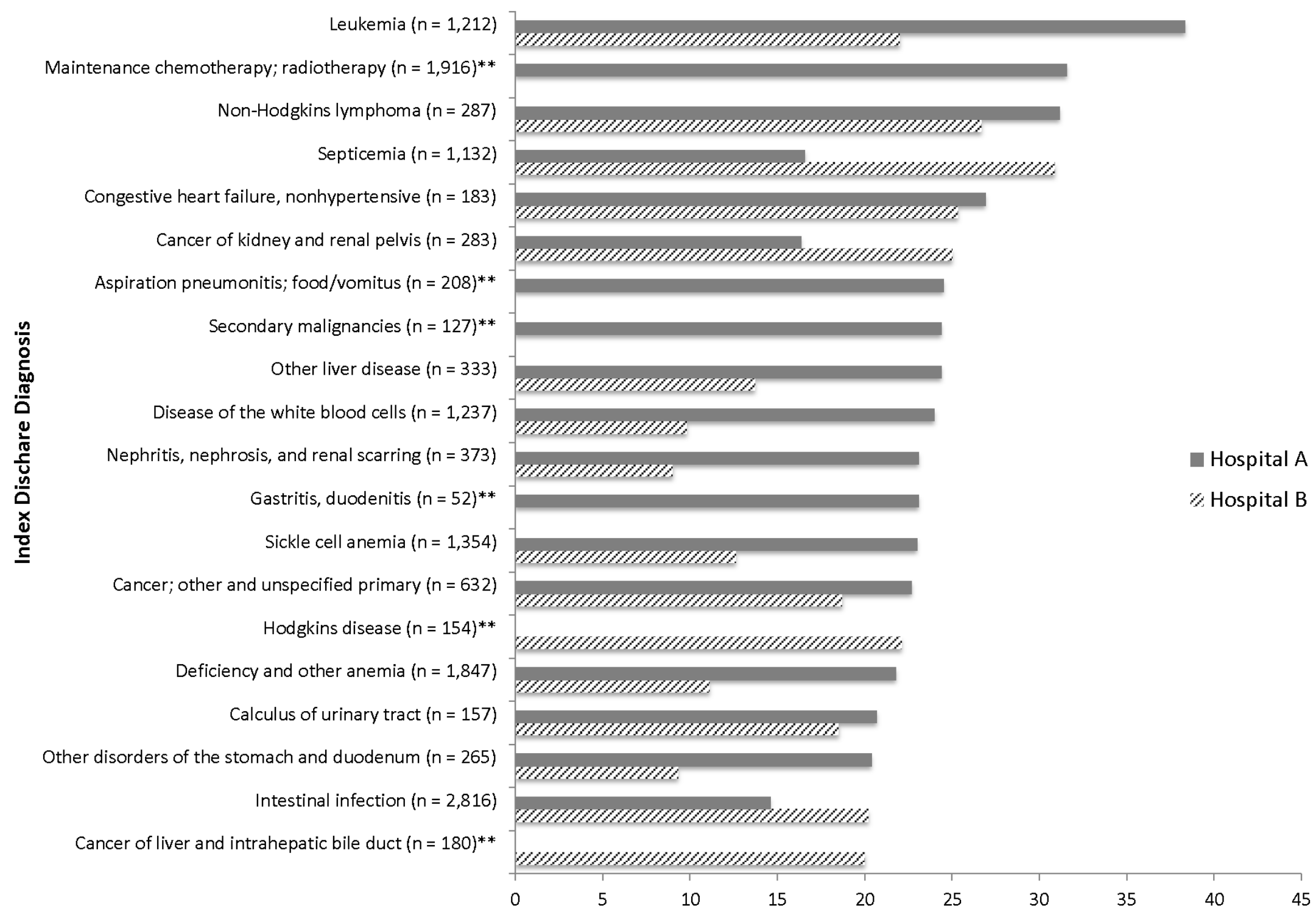

*Discharge diagnosis included in graph if the all cause readmission rate was $>20 \%$ at either hospital. Diagnoses only included in figure if there were at least 50 discharges at the hospital during the study period. Total combined number of discharges for both hospitals is shown above.

** Data from only one hospital are shown. There were $<50$ discharges at the other hospital. 


\section{Figure 3.Highest30-Day All Cause Readmission Rates by Index Discharge Diagnosis*}

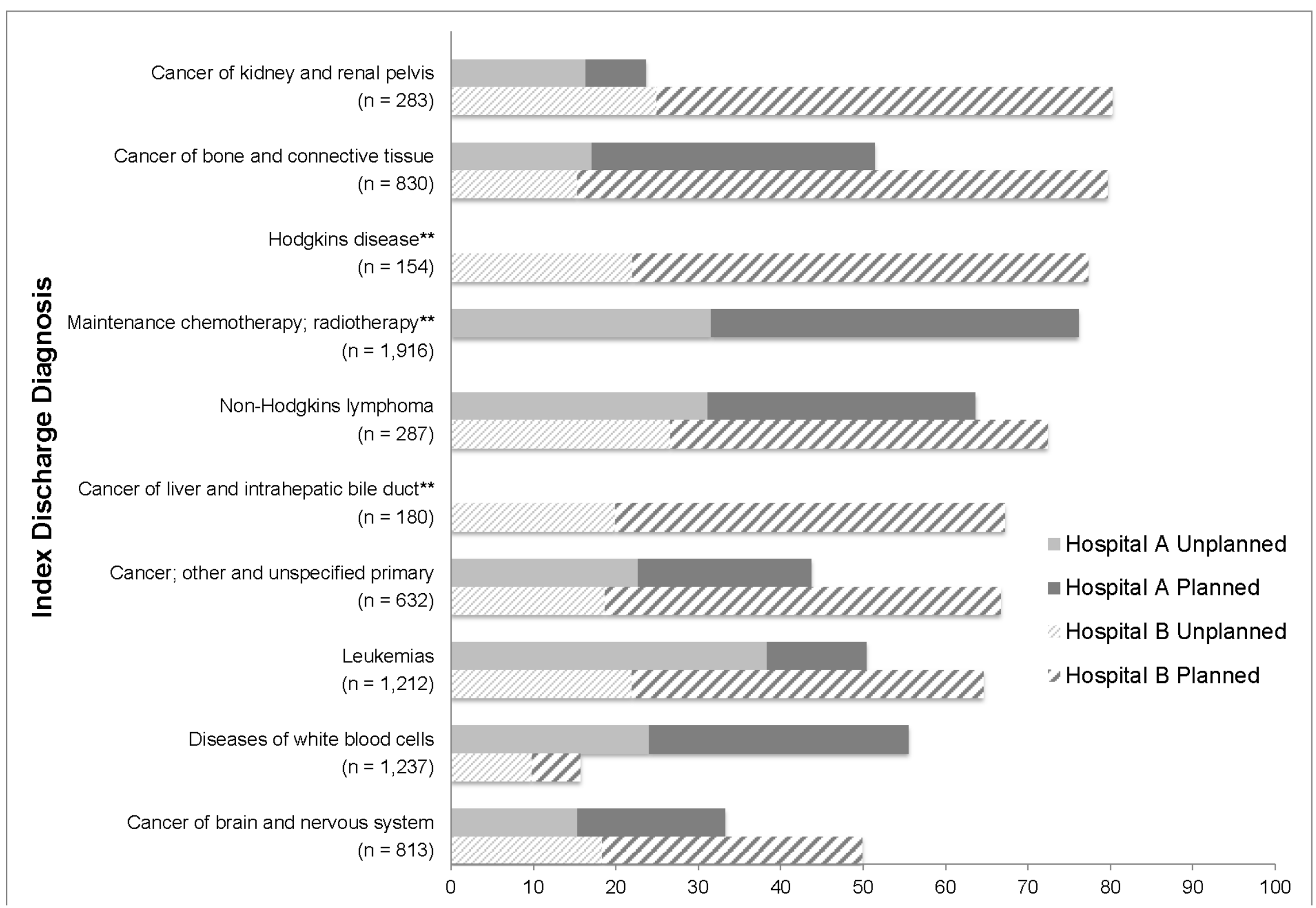

*Discharge diagnosis included in graph if the all cause readmission rate was $>50 \%$ at either hospital. Diagnoses only included in figure if there were at least 50 discharges at the hospital during the study period. Total combined number of discharges for both hospitals is shown above.

** Data from only one hospital are shown. There were $<50$ discharges at the other hospital. 


\section{Methods notes}

The clinical classification software labels both the codes for "Acute bronchiolitis due to other infectious organisms" and "Acute bronchiolitis due to respiratory syncytial virus (RSV)" as "Acute Bronchitis." Since $>99 \%$ of the diagnoses labeled as Acute Bronchitis were actually bronchiolitis codes, we have labeled them as bronchiolitis in the text.

Methods for table 1: All of the demographic characteristics in table 1 are patient level characteristics (i.e. patient attributes not admission attributes). Therefore, we randomly selected one index encounter per patient. We ran chi squared tests on the new randomly selected patientlevel dataset to determine if there were differences in demographic characteristics for patients readmitted versus not. We subsequently used bootstrapping(resampling over and over) to create multiple randomly selected datasets to obtain multiple $\mathrm{p}$ values for each demographic chi square test. We obtained $95 \%$ confidence intervals around the $\mathrm{p}$ value for the chi-square tests. We, conservatively, defined relationships as statistically significant if upper limit of the $95 \%$ confidence interval of the $p$ value was $<0.05$. 